\title{
Moderating Effect of Culture on Consumers' Usage of Social Networks and Its' Impact on Online Purchase Intentions
}

\author{
Sana Najib \\ Research Scholar, Karachi University Business School, University of Karachi, Pakistan \\ Dr. Danish Ahmed Siddiqui \\ Associate Professor, Karachi University Business School, University of Karachi, Pakistan
}

\begin{abstract}
This research explored the relationship between Perceived Usefulness and Perceived Ease of the use of Social Network and their impact on Online Purchase Intention moderated by Culture. The data of 384 consumers of online stores belonging to Karachi, Pakistan were taken thorough questionnaire and was analyzed using Structural Equation Modelling to identify the relationship between the said variables and the moderating effect of culture. The study found positive impact of perceived usefulness and perceived ease of use of social media use for online purchase intention. It also proved the moderating role of culture between use of social media and buying behavior. Thus, culture plays positive effect in influencing buying behavior through perceives usefulness and perceives ease of use.
\end{abstract}

Keywords: Perceived Usefulness, Perceived Ease of Use, Online Purchase Intention, Culture, SEM, Pakistan DOI: $10.7176 / \mathrm{JMCR} / 55-04$

Publication date: April $30^{\text {th }} 2019$

\section{INTRODUCTION}

\subsection{Background of the Study}

The internet has become one of the most important communication channels in the world and growing internet usage is motivating some changes in the consumer purchasing process (Casalo et al., 2007). Consumers are increasingly turning to social networks in order to get information on which to base their decisions (Kozinets, 2002). They are using several online formats (e.g., blogs, podcasts, social networks, bulletin boards, and wikis) to share ideas about a given product, service, or brand and contact other consumers, who are seen as more objective information sources (Kozinets, 2002).

This consumer-generated-content refers to online content that is produced by people, who were hitherto assumed to be only users or consumers of online content (Dwyer, 2007). The consumer-generated-media is defined as any positive $\backslash$ or negative statement about a product or service made by potential, actual, or former customers, which is available to a multitude of people and institutions via the Internet (Stauss, 2000).

The effect of interpersonal organizations is progressively inescapable, with exercises running from the financial (e.g., shopping) and showcasing (e.g., brand working) to the social (e.g., MySpace) what's more, instructive (e.g., remove training) (Teo et al., 2003). The generally short lived informal focused to one or a couple companions has been changed into suffering messages obvious to the whole world (Duan et al., 2008). Informal organizations permit associations to follow client assumption, client administration issues and disappointment in their client base.

For an effective shopping experience, consumers these days are utilizing technology at an increasing rate. A new world of collaboration and communication has been created; making shopping keeps its essence of a social and interactive activity. Online shopping at first, was seen as a monotonous experience since shopping is considered a fun and interactive thing to do by a mass, it is considered an activity where buyer and seller should be able to interact, share and communicate. Social media allows people to meet strangers and interactions that are not only limited to buyer and seller but also to third party consumers. This allows consumers to share their reviews with each other about products. Sharing of reviews or advocating for a product of store has heightened after social media. It was proven in a study that the number of consumers turning to social media for information about products is increasing. Not only have they turned up for information, but reviews from other user. Multiple researches have suggested that consumer reviews affect purchase decisions of potential consumers greatly, that combined with the mass reach and easy accessibility of social media and the wide acceptance of technology has made social networks' usage influence on consumer purchase a dilemma to be looked into.

The social part of shopping has been instilled in customer culture for quite a while with shopping seen as an outlet to mingle. Asking somebody where she understood that incredible outfit, hearing about the most recent deal from a companion or associating at the shopping center are all indispensable pieces of buyer culture. Informal communication has empowered purchasers to use innovation to "social shop" online consistently. With the expanded use of interpersonal organizations, it is critical to comprehend the impact of culture on the use of social organizing particularly with the wide spread notoriety of this innovation. Facebook's presentation of 
characteristic language interfaces in a few markets has pushed the site to $153 \%$ development, with a general utilization of online life developing to 25\% overall amid 2008 (Social Networking Explodes, 2008). Furthermore, Nielsen Global Online Consumer Survey (Global Publicizing, 2009) found that suggestions from individual colleagues or feelings posted by buyers online are the most confided in types of promoting around the world. Socially, every locale of the world is extraordinary; thus it is critical to get it regardless of whether informal communities has homogenized culture and made customers who think alike and act in a comparable style.

Innovation is, to a significant degree, socially and socially built (Schwarz and Thompson, 1990) and can't be isolated from people (Hendriks and Zouridis, 1999). Culture impacts way of life, and way of life impacts the way people convey and interface with new media advancements (Brandtzæg, 2010). Online informal communities have turned into a social marvel. Informal organizations, for example, Facebook and Myspace have seen a fast development in their enrollment, and with the expansion in notoriety of long range interpersonal communication sites, it is safe to state that the world is getting to be "littler" and individuals are presently between associated like never before.

Culture has been appeared to influence promoting, including publicizing, promoting systems and purchasing propensities (Green, 1999; Grier what's more, Brumbaugh, 1999; Simester et al., 2000; Taylor and Miracle, 1996; Ueltschy and Ryans, 1997b), however moderately minimal hypothetical what's more, experimental work is accessible in a culturally diverse adaption of developing innovation of interpersonal interaction. Culture as an indicator for online buy has brought about blended discoveries with respect to its sway on online buy conduct (Kim et al., 2009). While a few examinations prescribing on the web stores to adjust their atmospherics to the subtleties of a given culture (Chau et al., 2002). Cole et al. (2000) felt social contrasts don't influence online retailers' capacity to draw in and hold clients, referring to that set up online stores, for example, Amazon are comprehensively effective utilizing a institutionalized client interface. Culture and way of life profoundly impacts conduct and with a more prominent utilization of interpersonal interaction by people it is before long turning into the way of life of decision over ages and societies and should be analyzed all the more intently

\subsection{Problem Statement}

There is a more prominent feeling of criticalness for retailers to incorporate this new rising medium in their showcasing plan and make a social organize based procedure that is consistent with the brand and permits the organization to control the administration experience for their clients. Retailers are using the innovation accessible today to sell their items or administrations over the Internet, react to client questions, offer extra items and administrations dependent on past buys, and assess clients' fulfillment with their contributions-all without managing the client face to face (Kasim and Ismail, 2009). In any case, it is vital to take note of that informal organizations isn't a panacea and retailers should regard it as a impetus for crisp reasoning on how organizations can improve administration in the advanced age (Swartz, 2009). Informal organizations have put control in the buyers' hands and powers organizations to convey on their guarantees. The utilization of person to person communication by retailers to shape them administration technique is still in its early stages and should be investigated further particularly since arrangement of long range interpersonal communication technique what's more, administration technique is critical to the achievement of their business.

In a similar vein, buyers' utilization of informal communities for data, brand acknowledgment, and suppositions about brand or potentially retailers are impacted by their social foundation. Research has demonstrated that buyers contrast in their administration quality desire dependent on their way of life (Doonthu and Yoo, 1998). In general, customers' social qualities influence their desires and view of items or administrations, and in this manner, their buy decisions and purchasing conduct (Kueh and Voon, 2007). Utilizing deductive learning, it tends to be expressed that culture will likewise impact utilization of interpersonal organizations. Informal communication has given ascend to the "way of life of sharing" with people giving info on item and administrations for the general public's viewing pleasure. Given that culture may affect the manner in which individuals act and associate, it is basic to analyze societies' impact in long range interpersonal communication sites where a significant part of the data is typically client produced. Little or then again no work has been attempted to analyze social effect on long range informal communication which is progressively utilized by customers for sharing their encounters both great and awful.

There is an absence of data on how this new media combined with its worldwide intrigue is affecting buy conduct and should be inspected. The problem arises with the fact that consumer created information, about products and services can be positive or negative both. In the light of above, it clearly has a greater impact on people and also reaches a larger audience, it can be beneficial or destructive accordingly (Stauss, 2000 ).

Several companies aren't aware of the fact that these social networks means of information are actually affecting their customer base. The technologically equipped culture and the era of tagging, sharing and making things viral is effecting consumer purchase. This new culture is having an impact on how people react towards products and businesses. 
Companies need to be aware of the importance of cultural changes, spread of this new culture and its influence on social networking usage of consumers and the variables involved in leading out a positive or negative outcome of usage of social networks by consumers. This study aims to identify the significance of culture on social networks usage and its influence on the purchase intentions of consumers.Consequently, this paper advances an applied model that uses Hofstede's Cultural Dimensions $(1980,2001)$ and Venkatesh and Bala's (2008) Technology Acceptance.

\subsection{GAP ANALYSIS}

The Main Gaps we found in Previous study (Kozinets, 2002, Swedowsky, 2009, Mahoney, 2009, SocialNetwork-Driven, 2009) is to accumulate this two moderating effects of Culture and Social networking sites, Consumers are increasingly switch to social networks and this is effects on their purchase intentions and they like in order to get information from the internet, thus this effects affecting more on consumer in their buying decision (Kozinets, 2002), Swedowsky add it on that social networking has a potential to reached more audience and hence this influence more on consumer then culture effects. Consumer attracting towards social networks increasingly to learn more about brands (Mahoney, 2009)

Also some researcher focuses on culture as a main concern of Moderating effects. Culture has been shown to affect marketing, including advertising, marketing strategies and buying habits (Green, 1999; Grier and Brumbaugh, 1999; Simester et al., 2000; Taylor and Miracle, 1996; Ueltschy and Ryans, 1997), and some researchers adds on that Culture as a predictor for online purchase has resulted in mixed findings regarding its impact on online purchase behavior (Kim et al., 2009). While some studies recommending online stores to adapt their atmospherics to the nuances of a given culture (Chau et al., 2002). Cole et al. (2000).

In this study we focused on both the moderating effects in a positive way, that we believe that technology is supportive and social networking is also a positive influence in our society. Moreover, culture has its importance and the moderating effect. Nobody focuses earlier in these scenario and we aimed to explore the effects of Culture and intention to use Social networking sites and how much it can influence on Usefulness and Ease of social Networking sites.

\subsection{Research Objectives and Significance}

Deloitte Touche' USA uncovered that $62 \%$ of US customers read customer produced online surveys and $98 \%$ of them discover these surveys sufficiently dependable; $80 \%$ of these buyers said that perusing these audits has influenced their purchasing expectations (Industry insights, n.d.). Buyers have additionally begun using informal organizations progressively to become familiar with brands just as visit retail sites. For instance, the dynamic clients on Facebook, who on normal burn through $15 \mathrm{~h}$ on the site every week contributes over $3 \%$ of all traffic to the top retail locales on the web, with practically $25 \%$ of all the clients presenting joins on different organizations, items or administrations (Mahoney, 2009). Another examination by Jansen et al. (2009) found that $19 \%$ of the Twitter clients notice an association or item brand somehow or another in their "tweets" with about $20 \%$ of all microblogs referencing a brand, communicating a slant or conclusion worried that organization, item, or administration. Retailers are likewise pushing forward with consideration of social organizing in their advertising blend with $40 \%$ of e-retailers keeping up an informal organization page and $59 \%$ of top US retailers having a "fan page" on Facebook (Social-Network-Driven, 2009). Agreeing to Internet Retailer vast larger parts of the main 100 organizations had a profile on Facebook $(79 \%)$, Twitter $(69 \%)$ or both $(59 \%)$ (What's in a Retail email?, 2009). In this way, it very well may be induced that utilization of social organizing for shopping or "social shopping" is changing the retail industry particularly e-retail, empowered by purchaser innovation, client surveys and referrals, portable capacities and social organizing locales (Social-Network-Driven, 2009).

In Pakistan from the Past few years due to the boom in use of social networking sites many people are now familiar with the technology and that why now people of Pakistan are beginning to use internet and technology for the purpose of shopping, due to the change in this type of dynamics there is a flourishing opportunity for the Omnichannel. Retailers like Daraz successfully getting Billion-rupees profit milestone from its Black Friday, thus this Black Friday concept is not belonging to our Muslim culture but still it's successful just and give lots of benefits to the Daraz also another example of Food panda making huge profit with huge volume of 70,000 orders in four major cities of Pakistan, and it's also effecting our culture where people love to make foods for their love ones by their ownself (Rabbani F., 2018).

The purpose of this research is to examine the influence of Culture (Social Search, Subjective Norm and Self-Efficacy) on the Perceived Usefulness of Social Networks and Perceived Ease of Use of Social Network.

\subsection{Research Questions}

RO1: There is an influence of Perceived Usefulness of Social Networks and Perceived Ease of Use of Social Network on Online Purchase Intention?

RO2: There is an influence of Perceived Usefulness of Social Networks and Perceived Ease of Use of Social 
Network on Online Purchase Intention moderated by Culture?

RQ1: Is there an influence of Perceived Usefulness of Social Networks and Perceived Ease of Use of Social Network on Online Purchase Intention?

RQ2: Is there an influence of Perceived Usefulness of Social Networks and Perceived Ease of Use of Social Network on Online Purchase Intention moderated by Culture?

\subsection{Definitions}

Culture: A is a complex idea of cultural dimensions focusing on the individualism/collectivism, power distance, masculinity/femininity, uncertainty avoidance and short term/long term orientation.

Perceived Usefulness of Social Networks: The perceived extent of utility and involvement of social networks in the lives of individuals is known as perceived usefulness of Social Networks.

Perceived Ease of use of Social Networks: The extent to which, a person believes that the use of social networks will make their task easier or will enhance the quality of their work.

Intention of Using Social Networks: The degree of an individual at which they intend on using Social networks for shopping related activities.

Online Purchase Intention: The degree to which people intend to engaging in shopping activities and making a purchase online is the online purchase intention.

\section{LITERATURE REVIEW}

\subsection{Culture}

\subsubsection{Perceived Usefulness of Social Media linked to Culture}

Furrer et al. (2000) conducted a study on The Relationships between culture and social media usefulness on 431 university students. Findings showed that there is a strong relationship of culture, subjective norms, self-efficacy and individual/ collectivism on the perceived usefulness of social media.

Grier and Brumbaugh (1999) conducted a study on noticing cultural difference; ad meanings created by target and non-target market on social media from a population of social media users, sample of 350 visitors a online social media page based store were selected for this study. The data was collected through a selfadministered questionnaire. The collected data was processed through various statistical tests to determine the results. Findings showed that cultural differences make the perception of the target and non-target markets vary towards the advertisement. Consumer perception and interpretation of an ad is greatly influenced by the surrounding and cultural factors. (Grier \&Brumbaugh, 1999)

\subsubsection{Perceived Ease of Use of Social Media linked to Culture}

Kjelgaard and Askegaard (2006) conducted a study on the globalization of youth culture: the global youth segment as structures of common difference. From a population of university students, students of 4 universities were selected as respondents. A sample size of 389 students was selected as respondents for this research. The data was collected through a self-administered questionnaire. The collected data was processed through various statistical tests to determine the results. Findings showed that the localization of youth and the youth taking over the segments of market have restructured the market. The technological generation has reshaped the needs and wants of consumers and taken things to the technological advances.

Jarvenpaa and Tractinsky (1999) conducted a study on Consumer trust in an Internet store: a cross cultural validation. From a population of social media users, sample of 298 visitors a online social media page based store were selected for this study. The data was collected through a self-administered questionnaire. The collected data was processed through various statistical tests to determine the results. Findings showed that consumers trust on online shopping and online based stores varies from culture to culture. Consumers are more trusting on web based stores in the US than in China. (Jarvenpaa\&Tractinsky, 1999)

Chau et al. (2002) conducted a study on cultural differences in the online behavior of consumers. The purpose of the study was to determine the cultural differences that exist in the varying consumer behaviors online. A sample size of 256 individuals was selected. The data was collected through a self-administered questionnaire. The collected data was processed through various statistical tests to determine the results. Findings showed culture as an indicator for online buy has brought about blended discoveries in regards to its effect on online buy conduct. While a few studies prescribing on the web stores to adjust their atmospherics to the subtleties of a given culture (Chau et al., 2002).

\subsection{Social Media}

Technology these days is advancing and innovation is constant in all domains. Similarly, shopping has also shifted over time, integrating the use of new technology and social media in it. People have a natural desire to try the new innovations of the world. Thus, the Intention of Using Social Networks is

\subsubsection{Intention to Use Social Media linked to Perceived Usefulness of Social Media}

Clearly online networking has turned into a famous research field with the innovative headways and the Web 
multiplication. In this way, numerous scientists concentrate on and lead considers in online networking from alternate points of view, for example, administrative and political, showcasing, instructive, and person. From the administrative and political point of view, both Twitter and Facebook have picked up fame by governments and embraced by different lawmakers keeping in mind the end goal to be in a compelling and enduring correspondence with subjects.

Khan et al. (2014) studied the e-government to social government. Twitter use by Korea central government. The study was based in Korea, the tools used for data collection were focus groups of government officials and journalists. The collected data was processed through various statistical tests to determine the results. Findings characterize the administrations as social governments in this new period and express that governments ought to build up their web-based

\subsubsection{Intention to Use Social Media linked to Perceived Ease of Use of Social}

Lin et al. (2013) measure how understudies see Twitter as an instructive device. For this purpose, the population chosen were undergraduate students at university enrolled in business degree programs. A sample of 289 students was selected as respondents for this study. The data was collected through a self-administered questionnaire. The data collected from the survey was processed and results were obtained through various statistical tests. Findings showed that. They uncover that understudies are more inspired by data sharing about the courses through web-based social networking stages.

Prestridge (2014) likewise concentrate on understudies' Twitter use and demonstrates that Twitter bolster engagement in learning. For this purpose, the population chosen were undergraduate students at university enrolled in business degree programs. A sample of 315 students were selected as respondents for this study. The data was collected through a self-administered questionnaire. The data collected from the survey was processed and results were obtained through various statistical tests. Findings showed that student interaction increases with the use of social media. The socialization off campus has been decreased in face to face socialization. But has made the life of students easier to interact and inquire about subject matters over social media.

\subsection{Online Purchase Intention linked to Intention to Use Social Media}

Ozguven and Mucan (2013) concentrate on five identity attributes as in the investigation. They furthermore measure the impacts of salary, age, sex, and life fulfillment. For this purpose, the population chosen were undergraduate students at university enrolled in business degree programs. A sample of 330 students were selected as respondents for this study. The data was collected through a self-administered questionnaire. The data collected from the survey was processed and results were obtained through various statistical tests. They locate the noteworthy impacts of good faith, openness to involvement, instruction, salary level, and life fulfillment via web-based networking media utilize.

In expansion Rauniar et al. (2014) direct a review via web-based networking media utilization in view of TAM. They select Facebook as a case and attempt to discover the impacts of saw usability, minimum amount, ability, saw fun loving nature, saw handiness, and reliability via web-based networking media utilize. For this purpose, the population chosen were undergraduate students at university enrolled in business degree programs. A sample of 289 students were selected as respondents for this study. The data was collected through a selfadministered questionnaire. The data collected from the survey was processed and results were obtained through various statistical tests. They propose a changed TAM show by taking online networking into thought. They approve the model and locate the huge impacts of the reexamined measurements. 


\subsection{Conceptual Framework}

\section{Figure 1: Schematic Diagram}

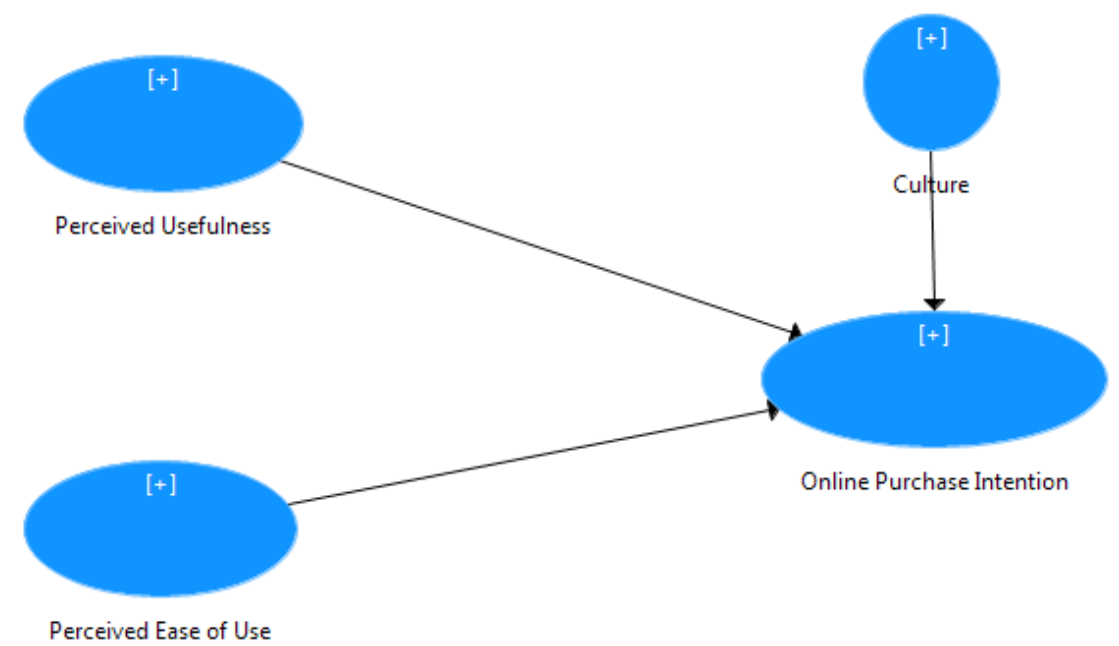

To empirically examine this research question we have developed the hypotheses which are:

Ha1: Perceived usefulness of social media will have an impact on Online purchase intention

\subsection{Hypotheses}

H1: Perceived usefulness of social media will have an impact on Online purchase intention

H3: Perceived usefulness of social media will have an impact on Online purchase intention when moderated by culture

Ha2: Perceived ease of use of social media will have an impact on Online purchase intention

Ha3: Perceived usefulness of social media will have an impact on Online purchase intention when moderated by culture

\section{METHODOLOGY}

\section{Population}

Population is defined as an entire set of individuals of a specified type. Samples are taken out of populations to predict results for the entire population. (Albright, Winston, \& Zappe, 2010). The population chosen for this research is all residents of Karachi. The sub-population for this research is selected under the assumption that only people living in the urban areas and from middle, upper middle and elite population of Karachi is aware of the existence and consumption of Counterfeit items.

\section{Sample Size}

A sample size of 384 individuals is chosen as respondents for this research, at a $95 \%$ confidence interval and 0.05 significance level (i.e. the results of the study will be true $95 \%$ of the time and there is a $5 \%$ error of margin). The sample size of 384 is adopted from the study conducted by Krejcie\& Morgan (1970), in which they created a formula that was used to derive the selected sample size. (Krejcie \& Morgan, 1970)

\section{Sampling Technique}

Sampling refers to the process of selecting a limited number of individuals from a large group or population that will represent the entire population. The purpose of sampling is to select a sample that minimizes the sampling error at its best and maximizes the chances of best representation of population in the selected sample size. (Chow, Wang, \& Shao, 2003)

Systematic sampling is a type of probability sampling method in which sample members from a larger population are selected according to a random starting point and a fixed periodic interval. This interval, called the sampling interval, is calculated by dividing the population size by the desired sample size. The systematic sampling technique is the best that can be used in the study. The respondents were selected for this study was at the fixed interval of every 5 th person in any place of all the five cities of Pakistan.

\section{Procedure of data collection}

The data will be collected in the general environment (field conditions) and no manipulated condition will be used in the data collection. The participants will be perceived as there were no deviations from the everyday routine when the data collected from the respondents. The research tool used in the study will be the selfadministrated questionnaire. There are 28 statements in the designed questionnaire. 4 statements were selected for variable "Culture (social pressure)", 4 statements were selected for variable "Culture (self-efficacy)",6 statements were selected for variable "Perceived usefulness", 5 statements were selected for variable "Perceived 
ease of use" , 4 statements were selected for variable "Intention to use " and 5 statements were selected for variable "Online purchase intention". All statements are measured on the 5-point Likert scale which tells that how the respondent strongly agrees or disagrees with the statement stated in the questionnaire.

\section{Results}

\section{Descriptive Statistic}

Descriptive Analysis has the purpose of providing a summary of the given data set and describing the data characteristics such as mean, median, mode, standard deviation, scatter plots, measure of skewed-ness and coefficient of variation etc. (Srivastava \& Rego, 2010)

\begin{tabular}{|c|c|c|c|c|}
\hline Questions & Variable & $\mathrm{N}$ & Mean & $\begin{array}{l}\text { Std. } \\
\text { Deviation }\end{array}$ \\
\hline \multicolumn{5}{|l|}{ Culture (social pressure) (suh2002) (bhatcherjee2000) } \\
\hline $\begin{array}{l}\text { My Peers/ colleagues thought that I should use social } \\
\text { networking sites }\end{array}$ & $\mathrm{C} 1$ & 384 & 3.31 & 1.047 \\
\hline $\begin{array}{l}\text { People I knew thought that using social networking sites was } \\
\text { a good idea }\end{array}$ & $\mathrm{C} 2$ & 382 & 3.7 & 0.836 \\
\hline Using this social networking site is a pleasant idea & $\mathrm{C} 3$ & 384 & 3.66 & 0.926 \\
\hline $\begin{array}{l}\text { People I knew influenced me to try out social networking } \\
\text { sites }\end{array}$ & $\mathrm{C} 4$ & 384 & 3.48 & 0.922 \\
\hline \multicolumn{5}{|l|}{ Culture (self-efficacy) (chen2007)(bhatcherjee2000) } \\
\hline $\begin{array}{l}\text { I would feel comfortable using social networking sites on } \\
\text { my own }\end{array}$ & $\mathrm{C} 5$ & 382 & 3.69 & 0.925 \\
\hline $\begin{array}{l}\text { I would be able to use social networking sites well on my } \\
\text { own }\end{array}$ & C6 & 381 & 3.89 & 0.708 \\
\hline I am satisfied with the technology when purchasing online & $\mathrm{C} 7$ & 381 & 3.44 & 1.185 \\
\hline $\begin{array}{l}\text { I would be able to use social networking sites even if there } \\
\text { was no one around to help me }\end{array}$ & $\mathrm{C} 8$ & 384 & 3.8 & 0.892 \\
\hline \multicolumn{5}{|l|}{$\begin{array}{l}\text { Perceived usefulness of social networking sites } \\
\text { (suh2002) }\end{array}$} \\
\hline $\begin{array}{l}\text { Using social networking enhances the productivity of my } \\
\text { shopping activities }\end{array}$ & PU1 & 377 & 3.65 & 0.992 \\
\hline $\begin{array}{l}\text { Using this social networking site has a critical role in } \\
\text { supporting my shopping activities. }\end{array}$ & PU2 & 376 & 3.53 & 1.022 \\
\hline $\begin{array}{l}\text { Using this social networking site makes it easier to do my } \\
\text { shopping activities }\end{array}$ & PU3 & 382 & 3.64 & 1.03 \\
\hline $\begin{array}{l}\text { Using this social networking enables me to accomplish } \\
\text { shopping activities more quickly }\end{array}$ & PU4 & 381 & 3.5 & 0.978 \\
\hline $\begin{array}{l}\text { Using this social networking site improves my performance } \\
\text { of shopping activities }\end{array}$ & PU5 & 381 & 3.5 & 1.035 \\
\hline $\begin{array}{l}\text { I find this social networking site useful for my shopping } \\
\text { activities }\end{array}$ & PU6 & 382 & 3.43 & 1.029 \\
\hline \multicolumn{5}{|l|}{$\begin{array}{l}\text { Perceived ease of use of social networking sites } \\
\text { (suh2002) }\end{array}$} \\
\hline $\begin{array}{l}\text { It is easy for me to learn how to utilize this social } \\
\text { networking site }\end{array}$ & PEOU1 & 382 & 3.78 & 0.925 \\
\hline $\begin{array}{l}\text { I find it easy to get this social networking site to do what I } \\
\text { want it to do }\end{array}$ & PEOU2 & 382 & 3.71 & 0.921 \\
\hline It is easy to remember how to use this social networking site & PEOU3 & 376 & 3.85 & 0.843 \\
\hline $\begin{array}{l}\text { My interaction with this social networking site is clear and } \\
\text { understandable }\end{array}$ & PEOU4 & 380 & 3.76 & 0.921 \\
\hline I find this social networking site easy to use & PEOU5 & 382 & 4.01 & 0.828 \\
\hline \multicolumn{5}{|l|}{ Online purchase intention (suh2002)(chen2007) } \\
\hline $\begin{array}{l}\text { It is likely that I will transact with this social networking site } \\
\text { for shopping in near future }\end{array}$ & OP1 & 382 & 3.7 & 1.008 \\
\hline $\begin{array}{l}\text { Given the chance, I intend to use this social networking site } \\
\text { for shopping }\end{array}$ & OP2 & 378 & 3.63 & 0.939 \\
\hline $\begin{array}{l}\text { Prior experiences make me believe in the future actions of } \\
\text { social networking site }\end{array}$ & OP3 & 382 & 3.69 & 0.751 \\
\hline
\end{tabular}




\begin{tabular}{|c|c|c|c|c|}
\hline $\begin{array}{l}\text { Prior experiences facilitate my purchase decision-making } \\
\text { process }\end{array}$ & OP4 & 382 & 3.72 & 0.87 \\
\hline $\begin{array}{l}\text { Given the chance, I predict that I should use this social } \\
\text { networking site for shopping in future }\end{array}$ & OP5 & 382 & 3.65 & 0.959 \\
\hline $\begin{array}{l}\text { I intend to continue using this social networking site in the } \\
\text { future }\end{array}$ & IUSM1 & 379 & 3.81 & 0.889 \\
\hline $\begin{array}{l}\text { I expect my use of this social networking site to continue in } \\
\text { the future }\end{array}$ & IUSM2 & 380 & 3.87 & 0.722 \\
\hline I will frequently use this social networking site in the future & IUSM3 & 383 & 3.72 & 0.856 \\
\hline $\begin{array}{l}\text { I will strongly recommend others to use this social } \\
\text { networking site }\end{array}$ & IUSM4 & 384 & 3.77 & 0.884 \\
\hline
\end{tabular}

The table above showed the minimum values, maximum values, sum, mean and values of the standard deviation of all variables. The number of observations for each variable is 349 . All mean values show the central tendencies of each variable. Standard deviation values, minimum and maximum, show the dispersion of values from their mean. There description is as followed

Culture:

For survey questions related with Culture, more than $60 \%$ voted agree for colleagues thought that I should use social networking sites and using social networking sites is a good idea, also 56\% agreed that Using this social networking site is a pleasant idea but just $28 \%$ believe that People I knew influenced me to try out social networking sites

The ratio of agree was found $40 \%$ however dis agree $35 \%$ related with comfortability of using social networking sites, also $41 \%$ voted for a satisfied with the technology when purchasing online.

\section{Perceived Usefulness of Social Networking Sites:}

Perceived usefulness also found as a good predictor, more than $52 \%$ believe that Using social networking enhances the productivity of their shopping activities also $72 \%$ believe Using this social networking site makes it easier to do my shopping, and $40 \%$ people think that social networking enhances the productivity of their shopping activities,

In survey we also found that $65 \%$ believe that social networking site useful for their shopping activities and $48 \%$ believe that social networking site improves their performance of shopping activities.

\section{Perceived Ease of Social Networking Sites:}

$75 \%$ agreed and strongly agreed that social networking sites are easy to use but only $41 \%$ believe or agreed that it easy to get this social networking site to do what they want it to do it makes their life easier, however the ratio of ease to learn how to utilize this social networking site was $53 \%$ in our survey report.

\section{Intention to Use Social Media:}

Intention to use social media not found that much supported as we seen Perceived ease and usefulness of social networking sites, as per our survey we found only $30 \%$ agreed to use social networking sites and intent to use social networking sites in the future, this might be the dynamics of environment which changes everything even the purchase intentions of the buyers, also $41 \%$ believe that frequently use this social networking site in the future and $31 \%$ are those who are in a favour to strongly recommend others to use this social networking site.

\section{Online Purchase Intention:}

The survey results show that just 35\% people likely transact with this social networking site for shopping in near future, while given a chance, 65\% agreed to intend to use this social networking site for shopping and 59\% predict that they should use this social networking site for shopping in future, also on Prior experiences $47 \%$ believe in the future actions of social networking site and $63 \%$ facilitate thier purchase decision-making process.

\section{Reliability}

After descriptive analysis we proceed for reliability test. The extent of the consistency of outcomes of a study, along with the accuracy in the representation of its total population is stated as reliability. A research instrument is only considered reliable when the same outcome can be reproduced of that study given that the methodology is similar. (Kirk \& Miller, 1986)

Reliability Scores $(\mathbf{N}=349)$

\begin{tabular}{|l|l|l|}
\hline Variables & No of Items & Cronbach's Alpha \\
\hline Culture & 8 & 0.792 \\
\hline Perceived Usefulness of Social Networking Sites & 6 & 0.854 \\
\hline Perceived Ease of Social Networking Sites & 5 & 0.985 \\
\hline Intention to Use Social Media: & 4 & 0.746 \\
\hline Online Purchase Intention: & 5 & 0.842 \\
\hline
\end{tabular}




\section{Reliability Statistic}

\begin{tabular}{|l|l|}
\hline Cronbach's Alpha & N of Items \\
\hline .853 & 28 \\
\hline
\end{tabular}

Reliability test was done to assess the significance of data (J. Nunnally, 1978; J. C. Nunnally \& Bernstein, 1994). In above table the values of reliability test show acceptable results with all items included. The reliability of all the variables including dependent and independent variables is greater than the cut off value that is 0.70 which was good (Santos, 1999). Overall Cronbach's Alpha of the questionnaire was 0.853 . Which is significant as it is greater than the cut off value which is 0.7 . Besides online purchase intention indicates 0.842 reliability which is also acceptable as it falls between the standard ranges of 0.5-0.9.

\section{CONFIRMATORY FACTOR ANALYSIS USING AMOS}

Many Different things need to be checked for the data appropriation for testing the model to make sure it is clearly represented the sufficient number and it is important to look variable-to-factor ration (Preacher \& MacCallum, 2002). It's Important to at least three items for each factors (Anderson \& Rubin, 1956), else it would be weak. However, most often contain one such factor also acceptable (Costello \& Osborne, 2005). Confirmatory factor analysis was performed using AMOS 25. Factor analysis was employed to reduce large number of variables to extract most underlying variables called factor. Confirmatory factor analysis is a useful method to examine the variability among observed variables and excerpt variability from items and load them into a common factor. As the study entails exploratory nature, factor analysis was done to identify the most important construct.

Figure: Confirmatory Factor Analysis Using Amos 25

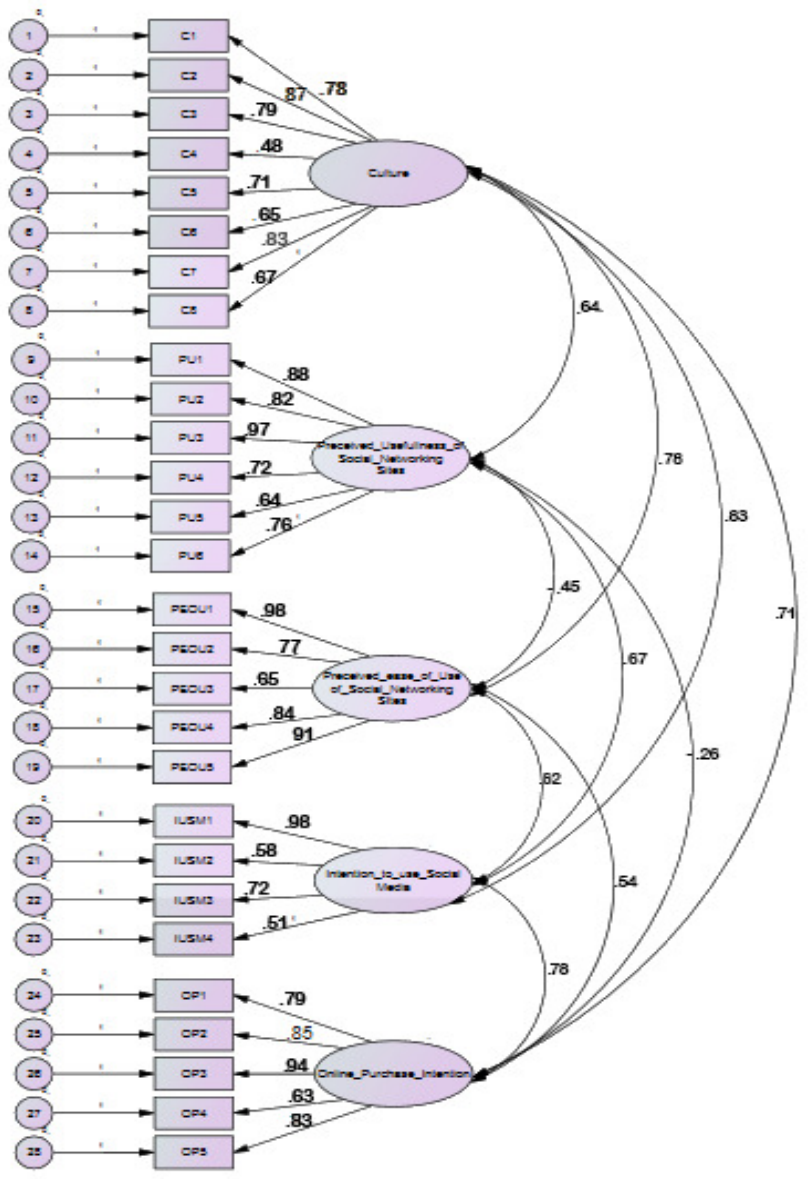




\begin{tabular}{|c|c|c|c|}
\hline $\begin{array}{l}\text { Latent } \\
\text { Variable }\end{array}$ & $\begin{array}{l}\text { Item } \\
\text { Label }\end{array}$ & Item Description & $\begin{array}{l}\text { Standardized } \\
\text { Factor } \\
\text { Loading } \\
\end{array}$ \\
\hline C1 & Q1 & My Peers/ colleagues thought that I should use social networking sites & 0.78 \\
\hline $\mathrm{C} 2$ & Q2 & People I knew thought that using social networking sites was a good idea & 0.87 \\
\hline $\mathrm{C} 3$ & Q3 & Using this social networking site is a pleasant idea & 0.79 \\
\hline $\mathrm{C} 4$ & Q4 & People I knew influenced me to try out social networking sites & 0.48 \\
\hline $\mathrm{C5}$ & Q5 & I would feel comfortable using social networking sites on my own & 0.71 \\
\hline C6 & Q6 & I would be able to use social networking sites well on my own & 0.65 \\
\hline C7 & Q7 & I am satisfied with the technology when purchasing online & 0.83 \\
\hline $\mathrm{C} 8$ & Q8 & $\begin{array}{l}\text { I would be able to use social networking sites even if there was no one } \\
\text { around to help me }\end{array}$ & 0.67 \\
\hline PU1 & Q9 & Using social networking enhances the productivity of my shopping activities & 0.88 \\
\hline PU2 & Q10 & $\begin{array}{l}\text { Using this social networking site has a critical role in supporting my } \\
\text { shopping activities. }\end{array}$ & 0.82 \\
\hline PU3 & Q11 & Using this social networking site makes it easier to do my shopping activities & 0.97 \\
\hline PU4 & Q12 & $\begin{array}{l}\text { Using this social networking enables me to accomplish shopping activities } \\
\text { more quickly }\end{array}$ & 0.72 \\
\hline PU5 & Q13 & $\begin{array}{l}\text { Using this social networking site improves my performance of shopping } \\
\text { activities }\end{array}$ & 0.64 \\
\hline PU6 & Q14 & I find this social networking site useful for my shopping activities & 0.76 \\
\hline PEOU1 & Q15 & It is easy for me to learn how to utilize this social networking site & 0.98 \\
\hline PEOU2 & Q16 & I find it easy to get this social networking site to do what I want it to do & 0.77 \\
\hline PEOU3 & Q17 & It is easy to remember how to use this social networking site & 0.65 \\
\hline PEOU4 & Q18 & My interaction with this social networking site is clear and understandable & 0.84 \\
\hline PEOU5 & Q19 & I find this social networking site easy to use & 0.91 \\
\hline OP1 & Q20 & I intend to continue using this social networking site in the future & 0.98 \\
\hline OP2 & Q21 & I expect my use of this social networking site to continue in the future & 0.68 \\
\hline OP3 & Q22 & I will frequently use this social networking site in the future & 0.72 \\
\hline OP4 & Q23 & I will strongly recommend others to use this social networking site & 0.51 \\
\hline OP5 & Q24 & $\begin{array}{l}\text { It is likely that I will transact with this social networking site for shopping in } \\
\text { near future }\end{array}$ & 0.79 \\
\hline IUSM1 & Q25 & Given the chance, I intend to use this social networking site for shopping & 0.86 \\
\hline IUSM2 & Q26 & $\begin{array}{l}\text { Prior experiences make me believe in the future actions of social networking } \\
\text { site }\end{array}$ & 0.94 \\
\hline IUSM3 & Q27 & Prior experiences facilitate my purchase decision-making process & 0.63 \\
\hline IUSM4 & Q28 & $\begin{array}{l}\text { Given the chance, I predict that I should use this social networking site for } \\
\text { shopping in future }\end{array}$ & 0.83 \\
\hline
\end{tabular}

The above table shows Standardized factor loading for each item and shows the association between individual items with the extract construct. Factor loading for each item depicts reasonable to strong relationship with the underlying construct.

\section{EVALUATING MEASUREMENT MODEL FITNESS}

To evaluate the fitness of the proposed model, Amos delivers a set of useful indices that are used to determine the fitness and validity of the hypothesized model. Out of different significant indices, root mean square error of approximation (RMSEA), goodness of fit index (GFI), Chi-Square, CMIN/DF, adjusted goodness of fit index (AGFI), and comparative fit indices were observed to determine the authenticity of the research model. The discussed indices show the degree to which constructs are related to one another. Below Table and CFA diagram demonstrate the resultant values. 


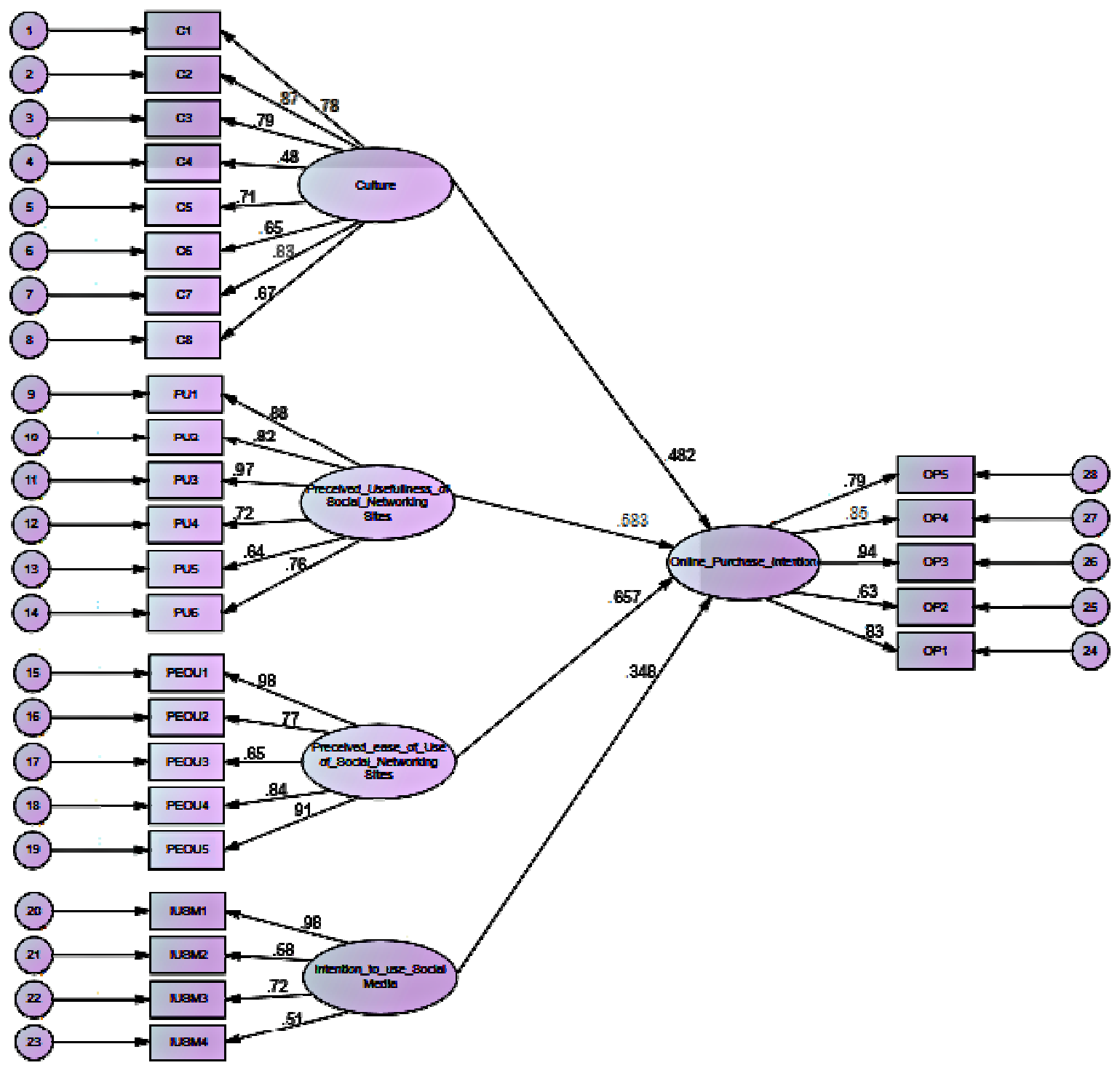

Model Fitness Test

\begin{tabular}{|l|l|l|}
\hline Model Fit & Resultant Value & Threshold \\
\hline CMIN/DF & 3.268 & $<3$ good ; $<$ Acceptable \\
\hline CFI & 0.890 & Closer to 1; good \\
\hline GFI & 0.911 & $>0.90$ \\
\hline AGFI & 0.903 & $>0.90$ \\
\hline RMR & 0.072 & $<0.08$ \\
\hline RMSEA & 0.076 & $<0.08$ \\
\hline
\end{tabular}

STRUCTURAL EQUATION MODELING

Structural equation modeling used to evaluate the structural relationship between exogenous and endogenous variables. The structural equation modeling includes factor analysis and multivariate analysis of the model. Firstly, we evaluate the model fitness and measure whether the paths showing the relationship between measured and latent variables are significant or not. The SEM diagram showed in below figure. In this diagram Culture, Perceived Usefulness of social networking sites, Perceived Ease of use of social networking sites, Intention to Use social media towards online Purchase Intention. Besides table shows the model fit results by analyzing model fit indices.

To evaluate the fitness of the proposed model, Amos delivers a set of useful indices that are used to determine the fitness and validity of the hypothesized model. Out of different significant indices, root mean square error of approximation (RMSEA), goodness of fit index (GFI), Chi-Square, CMIN/DF, adjusted goodness 
of fit index (AGFI), and comparative fit indices were observed to determine the authenticity of the research model. The discussed indices show the degree to which constructs are related to one another.

EVALUATING MEASUREMENT MODEL FITNESS

Model Fitness Test

\begin{tabular}{|l|l|l|}
\hline Model Fit & Resultant Value & Threshold \\
\hline CMIN/DF & 2.905 & $<3$ good ; $<$ Acceptable \\
\hline CFI & 0.913 & Closer to 1; good \\
\hline GFI & 0.976 & $>0.90$ \\
\hline AGFI & 0.923 & $>0.90$ \\
\hline RMR & 0.064 & $<0.08$ \\
\hline RMSEA & 0.071 & $<0.08$ \\
\hline
\end{tabular}

The calculated value of CMIN/DFI is 2.905 which shows a good model fit. The values of CFI, RMSEA, specifies that the proposed model was statistically fit as these parameters resultant values meets threshold as explained in the above table.

Regression Weights (Hypothesis Testing)

\begin{tabular}{|l|l|l|l|l|l|l|l|}
\hline \multicolumn{2}{|l|}{} & Estimate & SE & CR & P & \\
\hline Purchase_Intention & $<---$ & Culture & 0.482 & 0.065 & 3.049 & 0.000 & H1 Accepted \\
\hline Purchase_Intention & $<---$ & PU & 0.583 & 0.012 & 16.11 & 0.000 & H2 Accepted \\
\hline Purchase_Intention & $<---$ & PEOU & 0.657 & 0.135 & 0.329 & 0.000 & H3 Accepted \\
\hline Purchase_Intention & $<---$ & IUSM & 0.348 & 0.113 & -1.75 & 0.000 & H4 Accepted \\
\hline
\end{tabular}

The above table illustrate the influence of Culture, Perceived Usefulness of social networking sites, perceived ease of social networking sites and intentions to use social networking predictors on online Purchase. Each independent predictor gives an unstandardized and standardized beta coefficient that predicts the positive or negative impact of each variable. While $p$-value measures significance of data at $95 \%$ confidence interval.

First, 'Culture' has a positively influence on 'Purchase Intention' $(\beta=0.482, p<.001)$, therefore H1 is accepted. Second, 'Perceived Usefulness of Social Networking sites' also has a positively influence on 'Purchase Intention"' $(\beta=0.583, p<.001)$, therefore H2 is accepted. Third, 'Perceived ease of social networking sites' has also Positively influence on 'Purchase Intention'" $(\beta=0.657, p>.001)$, therefore H3 is also accepted, Last 'Intention to use Social networking sites' also Positively influence on 'Purchase Intention' $(\beta=0.348, p>.001)$, therefore $\mathrm{H} 4$ is also accepted.

\section{Discussions}

Culture is an adroitly mind boggling thought that has challenged a far reaching and concurred on definition (Lam et al., 2009). Hofstede's fundamental work $(1980,2001)$ concentrated on the social measurements of independence, control separate, manliness, vulnerability shirking and long haul introduction. Independence is characterized as how much a general public stresses the job of the person. Power separate is how much the less amazing individuals from associations acknowledge that control is appropriated unequally. Manliness is how much a general public underlines custom manly qualities rather than ladylike values. Vulnerability evasion is the degree to which individuals feel threatened by unstructured and ambiguity. Lastly, long term orientation is defined as the extent to which a society exhibits a pragmatic, future-oriented perspective rather than a conventional historic or short-term perspective (Hofstede, 2001). Individualism, uncertainty avoidance, and long term avoidance are the three dimensions of culture that will be included in this study.

From our Study we found culture has positively influence in purchase intetions which is supported the theories of Dwyer et al., 2005, individuals in short-term orientation cultures experience materialist consumption pressures (i.e. keeping up with trends such as social networking) and adopt new technology rapidly. It's also contradict the theory of (Stremersch and Tellis, 2004; Yaveroglu and Donthu, 2002.

Social orders that are high in vulnerability evasion consistently feel the inborn vulnerability throughout everyday life while social orders low in vulnerability evasion all the more effectively acknowledge vulnerability (Stremersch and Tellis, 2004; Yaveroglu and Donthu, 2002). Moreover, vulnerability shirking is identified with clients' hazard observation (Jarvenpaa and Tractinsky, 1999) and therefore we can induce that relying upon their dimension of vulnerability shirking buyers will respond distinctively to towards long range informal communication.

Ease of social Networking is also positively influence Purchase intention which support these theories. Srite and Karahanna's (2006) ponder tried a model in which Hofstede's four fundamental social measurements directed the connections among PU and PEOU. The consequence of the investigation found that just manliness - womanliness measurement directed the relationship among PEOU and expectation. Furthermore, Karahanna et al's. (2005) consider recommended that culture can direct the relationship between emotional 
standard and the conduct expectation.

Interpersonal interaction is conveying changes to correspondence designs and relational connections (Byrne, 2007; Hargittai, 2007; Humphreys, 2007). Person to person communication is a late wonder and its multiplication and becoming social sway is affirmation of the developing impact of innovation on the customer choice procedure. Person to person communication permits associations to take part in opportune and direct endcustomer contact at generally minimal effort and larger amounts of proficiency making it an extremely appealing option in contrast to the more customary specialized instruments (OECD, 2007).

\section{Conclusion}

From this examination we can reason that the study concluded that online shopping has many advantages and have significant impact on respondent's intention to shop on the web. This finding additionally bolstered internet shipping intention taking a gander at the normal score of respondents. Subsequently we can reason that respondents are expect to shop online in view of its of advantage as well as a result of culture and condition elements and high perceived ease of utilization. This review result likewise upheld past looks into which expressed that usefulness is the essential component that impact acknowledgment of specific innovation yet in this examination it is found that usefulness calculate has significant impact on repurchase intention.

The PEOU is perceived high and makes respondents plan to shop on the web. In conclusion understudies expect to shop online as a result of ease in web based shopping, as can be seen in respondent attributes that they have utilized web for over 3 years and interface with the web between 2-4 hours, yet this is for the most part created by culture and condition conditions figures additionally high perceived usefulness in online shopping.

The buyers' aim to utilize another innovation like person to person communication is influenced by two convictions: (1) Perceived Usability (PEOU) and (2) Perceived Usefulness (PU). The previous concerns "how much an individual trust that utilizing a specific framework would improve his or her activity execution" (Davis, 1989); while the last mirrors how much a individual trusts that utilizing a specific framework would be free of exertion (Davis, 1989). In our model, PEOU and PU are inspected with connection to utilizing informal organizations by customers. The model recommends that PU will be impacted by apparent usability since, different things being equivalent, the simpler an innovation is to use, the more valuable it tends to be (Venkatesh, 2000) by and large PEOU affects goal (Lee et al., 2003). PU is a solid indicator of conduct goal (Venkatesh and Bala, 2008) which in this examination is the goal to utilize social systems for internet shopping.

Culture impacts how Individuals think and see an occasion and informal communication is a monstrous union of culture, shining a different light on essential social terms as "learning," "astuteness," "specialist," "trust" furthermore, "social transmission of significance" (Maj and Derda- Nowakowski, 2009). Long range informal communication has permitted the development of new culture where it is never again formed just by singular qualities and belief systems yet additionally by new customs and specialized apparatuses in the social space of Web 2.0

As indicated by eMarketer, the quantity of individuals making content online will ascend from 88.8 million out of 2009 to 114.5 million out of 2013 (The Future of User-Generated Content, 2010). Purchasers through informal organizations are applying an undeniably significant impact over culture and economy, with different businesses changing the manner in which they work together. Retail industry is a prime case of this marvel with over $81 \%$ of individuals utilizing customer audits in their buy choices (Leggatt, 2009). Interpersonal organizations are giving retailers a chance to come to another assortment of buyers. Data produced by purchasers in a informal community stage is an extensive included an incentive for other clients and absence of such data on a retailer's site would cause them to look for data, and perhaps items, somewhere else (Vreeland, 2010). In this manner, it very well may be unmistakably expressed that not joining informal organizations as a piece of the promoting blend isn't as it were poor client administration, yet additionally a surefire approach to lose purchasers.

Culture has not been given its due while looking at effect on new innovation. Effective advertisers are progressively perceiving culture as the most dominant determinant of buyer frames of mind, ways of life, and practices (Cleveland and Chang, 2009). Furthermore, retailers must address the likelihood of social heterogeneity and homogeneity inside and crosswise over nations and societies (Broderick et al., 2007; Tung, 2008; Yavas et al., 1992). Social gatherings and social marvel, for example, utilization of social arranges crosswise over nations are liable to proceeded with impact by worldwide culture which reshapes people's 'individual' societies along these lines fortifying the legitimacy of level worldwide fragments (Eckhardt and Houston, 2007; Kjeldgaard and Askegaard, 2006; Malhotra et al., 1996). Using an examination that consolidates culture as both an indicator just as an arbiter variable to new innovation acknowledgment will include critical new data and hypothesis to this rising territory of research. Retailers must tune in to what's more, draw in their clients through informal communities by taking an interest what's more, promising discussions. The final product will improve client administration and will help transform steadfast clients into enthusiastic backers.

An overview led by American Marketing Association showed 47\% of the purchasers would visit person to person communication locales to look for and talk about occasion blessing thoughts, and $29 \%$ said they would 
purchase items there (Horovitz, 2006). Informal organizations using social shopping applications can possibly change the clothing retail scene. Informal organizations permit buyers to grasp the inborn social nature of shopping by not just giving applicable data through postings on the web however go past the conventional domain by fulfilling significantly more gluttonous needs: the requirement for endorsement from companions, the longing for self-articulation, and the longing for amusement (Cohn and Park, 2007). People embrace developments with for the most part private individual, singular outcomes and, regardless of whether an individual considers an advancement for reception is unequivocally controlled by similarity between the qualities of an advancement and the necessities of the individual (Valente and Rogers, 1995). In the present associated world it is sheltered to expect that informal organizations are a vital innovation advancement that straightforwardly sway purchasers and in the long run will affect their recognition with respects to acquiring expectation on the web.

\section{Future Recommendations}

In spite of the exploratory way of this review, it figured out how to clarify on the norm of Internet shopping through adequate experimental research. The recognition builds of perceived usability and perceived value must be explored in light of the sort of items that are planned to be obtained by the Internet customer. As a proposal, things must be isolated into their capacities, thus, enabling a record to be agreed to each of them in view of the significance of both the observation develops. Henceforth, a gauge can be thought about the amount of impact that is included in every observation build. Future replications of this model should seriously consider over exploring the mediating impact of perceived usefulness on the connection between perceived ease of use and goal to shop online relationship.

Outside components of item esteem, client administration and purchaser dangers ought to likewise be consolidated as forerunners into future repeated models. For example, Madu and Madu (2002) streamlined equality measurements into site execution, highlights, structures, feel, unwavering quality, stockpiling capacity, responsibility, security, confide in, responsiveness, item separation and customization, approaches, notoriety, affirmation and compassion that can be viewed as outer variables. Other outer variables that could be analyzed are item data, client benefit, buy result and conveyance, site configuration, acquiring process, item merchandizing, conveyance time and charge, convenience and extra data administrations (Cho and Park, 2002).

\section{References}

Ajzen, I., (1991). The theory of planned behavior.Organizational Behavior and Human Decision Processes 50 (2), 179-211.

Argo, J.J., Dahl, D.W., Morales, A.C., (2006). Consumer contamination: how consumers react to products touched by others. Journal of Marketing 70 (2), 81-94.

Argo, J.J., Dahl, D.W., Morales, A.C., (2008). Positive consumer contagion: responses to attractive others in a retail context. Journal of Marketing Research 45 (6), 690-701.

Bandura, A.(1982). Self-efficacy mechanism in human agency.American Psychologist 37 (2), 122-147.

Bandura, A. (2007). Much ado over faulty conception of perceived self-efficacy grounded in faulty experimentation. Journal of Social and Clinical Psychology 26 (6), 641-758.

Bearden, W.O., Netemeyer, R.G., Teel, J.E.(1989). Measurement of consumer susceptibility to interpersonal influence. Journal of Consumer Research 15 (4), 473-481.

Bell, D.R., Song, S. (2007). Neighborhood effects and trial on the internet: evidence from online grocery retailing. Quantitative Marketing and Economics 5 (4), 361-400.

Brandtzg, P.B.(2010). Towards a unified Media-User Typology (MUT): a meta analysis and review of the research literature on media-user typologies. Computers in Human Behavior 26 (5), 940-956.

Broderick, A.J., Greenley, G.E., Mueller, R.D. (2007). The behavioral homogeneity evaluation framework: multi-level evaluations of consumer involvement in international segmentation. Journal of International Business Studies 38 (5), 746-763.

Byrne, D.N., (2007). Public discourse, community concerns, and civic engagement: exploring black social networking traditions on BlackPlanet.com. Journal of Computer-Mediated Communication 13 (1), 319-340.

Casalo, L., Flavian, C., Guinaliu, M., (2007). The impact of participation in virtual brand communities on consumer trust and loyalty. The case of free software.Online Information Review 31 (6), 775-792.

Chau, P.Y.K., Cole, M., Massey, A.P., Montoya-Weiss, M., O’Keefe, R.M., (2002). Cultural differences in the online behavior of consumers. Communications of the ACM 45 (10), 138-143.

Cleveland, M., Chang, W.(2009). Migration and materialism: the roles of ethnic identity, religiosity, and generation. Journal of Business Research 62 (10), 963-971.

Cole, M., O'Keefe, R.M., Siala, H.(2000). From the user interface to the consumer interface. Information Systems Frontiers 53 (4), 349-361.

Davis, F.D.(1989). Perceived usefulness, perceived ease of use, and user acceptance of information technology. 
MIS Quarterly 13 (3), 319-340.

Davis, F.D., Venkatesh, V.(2004). Toward preprototype user acceptance testing of new information systems: implications for software project management. IEEE Transactions on Engineering Management 51 (1), 3146.

Duan, W., Gu, B., Whinston, A.B.(2008). The dynamics of online word-of-mouth and product sales-an empirical investigation of the movie industry. Journal of Retailing 84 (2), 233-242.

Donthu, N., Yoo, B.(1998). Cultural influences on service quality expectations. Journal of Service Research 1 (2), 178-186.

Dwyer, P.(2007). Measuring the value of electronic word of mouth and its impact in consumer communities. Journal of Interactive Marketing 21 (2), 63-79.

Dwyer, S., Mesak, H., Hsu, M.(2005). An exploratory examination of the influence of national culture on crossnational product diffusion. Journal of International Marketing 13 (2), 1-27..

Furrer, O., Liu, B.S.-C., Sudharshan, D.(2000). The Relationships between culture and service quality perceptions. Journal of Service Research 2 (4), 355-371.

Gershoff, A.D., Mukherjee, A., Mukhopadhyay, A.(2003). Consumer acceptance of online agent advice: extremity and positivity effects. Journal of Consumer Psychology 13 (1\&2), 161-170.

Green, C.(1999). Ethnic evaluations of advertising: interaction effects of strength of ethnic identification, media placement and degree of racial composition. Journal of Advertising 28 (1), 49-64.

Grier, S.A., Brumbaugh, A.M.(1999). Noticing cultural differences: ad meanings created by target and nontarget markets. Journal of Advertising 28 (1), 79-93.

Ha, S., Stoel, L.(2009). Consumer e-shopping acceptance: antecedents in a technology acceptance model. Journal of Business Research 62 (5), 565-571.

Hargittai, E.(2007). Whose space? differences among users and non-users of social network sites. Journal of Computer-Mediated Communication 13 (1), 276-297.

Haubl, G., Murray, K.(2003). Preference construction and persistence in digital marketplaces: The role of electronic recommendation agents.Journal of Consumer Psychology 13 (1), 75-91.

Haubl, G., Trifts, V.(2003). Information availability and consumer preference: Can online retailers benefit from providing access to competitor price information? Journal of Consumer Psychology 13 (2), 149-159.

Humphreys, L.(2007). Mobile social networks and social practice: a case study of dodgeball. Journal of Computer-Mediated Communication 13 (1), 341-360.

Jansen, B.J., Zhang, M., Sobel, K., Chowdhury, A.(2009). Twitter power: tweets as electronic word of mouth. Journal of the American Society for Information Science and Technology 60 (11), 2169-2188.

Jarvenpaa, S.L., Tractinsky, N.(1999). Consumer trust in anInternet store: a cross $\neg$ cultural validation. Journal of Computer Mediated Communication 5 (2), 1-35.

Karahanna, E., Evaristo, J.R., Srite, M.(2005). Levels of culture and individual behavior: an integrative perspective. Journal of Global Information Management 13 (2), 1-20.

Kasim, N.M., Ismail, S.(2009). Investigating the complex drivers of loyalty in e-commerce settings. Measuring Business Excellence 13 (1), 56-71.

Kozinets, R.V.(2002). The field behind the screen: using netnography for marketing research in online communities. Journal of Marketing Research 39 (1), 61-72.

Kjeldgaard, D., Askegaard, S.(2006). The glocalization of youth culture: the global youth segment as structures of common difference. Journal of Consumer Research 33 (2), 231-247.

Kucuk, S.U., Krishnamurthy, S.(2007). An analysis of consumer power on the internet. Technovation 27 (1/2), 47-56.

Kueh, K., Voon, B.H.(2007). Culture and service quality expectations: evidence from generation $\mathrm{Y}$ consumers in Malaysia.Managing Service Quality 17 (6), 656-680.

Lam, D., Lee, A., Mizerski, R., 2009. The effects of cultural values in word-of-mouth communication. Journal of International Marketing 17 (3), 55-70.

Lee, Y., Kozar, K., Larsen, K.(2003). The technology acceptance model: past, present, and future. Communications of the AIS 12 (50), 752-780.

Lim, H., Dubinsky, A.J.(2005). Determinants of consumers' purchase intention on the Internet: an application of theory of planned behavior. Psychology and Marketing 22 (10), 833-855.

Malhotra, N.K., Agarwal, J., Peterson, M.(1996). Methodological issues in cross $\neg$ cultural marketing research: a state of the art review. International Marketing Review 13 (5), 7-43.

Manski, C.F.(1993). Identification of endogenous social effects: the reflection problem. Review of Economic Studies 60 (3), 531-542.

Manski, C.F.(2000). Economic analysis of social interactions.Journal of Economic Perspectives 14 (3), 115-136.

Mathieson, K.(1991). Predicting user intentions: comparing the technology acceptance model with the theory of planned behavior. Information Systems Research 2 (3), 173-191. 
McAlexander, J.H., Schouten, J.W., Koenig, H.F.(2002). Building brand community.Journal of Marketing 66 (1), 38-54.

Sawhney, M., Verona, G., Prandelli, E.(2005). Collaborating to create: the internet as a platform for customer engagement in product innovation. Journal of Interactive Marketing 19 (4), 4-17.

Simester, D.I., Hauser, J.R., Wernerfelt, B., Rust, R.T.(2000). Implementing quality improvement programs designed to enhance customer satisfaction: quasi $\neg$ experiments in the United States and Spain. Journal of Marketing Research 37 (1), 102-112.

Srite, M., Karahanna, E.(2006). The influence of national culture on the acceptance of information technologies: an empirical study. MIS Quarterly 30 (3), 679-704.

Stauss, B.(2000). Using new media for customer interaction: a challenge for relationship marketing. In: Henning-Thurau, T., Hansen, U. (Eds.), Relationship Marketing.

Stremersch, S., Tellis, G.J.(2004). Understanding and managing international growth of new products. International Journal of Research in Marketing 21 (4), 421-438.

Swaminathan, V.(2003). The impact of recommendation agents on consumer evaluation and choice: the moderating role of category risk, product complexity and consumer knowledge. Journal of Consumer Psychology, Special Issue on Consumers in Cyberspace 13 (12), 93-101.

Taylor, S., Todd, P.A.(1995). Understanding information technology usage: a test of competing models. Information Systems Research 6, 144-176.

Teo, H.H., Chan, H.C., Weib, K.K., Zhang, Z.(2003). Evaluating information accessi $\neg$ bility and communityadaptivity features for sustaining virtual learning communities. International Journal of HumanComputer Studies 59 (5), 671-697.

Triandis, H.C.(1989). The self and social behavior in differing cultural contexts.Psychological Review 96 (3), 506-520.

Tung, R.L.(2008). The cross-cultural research imperative: the need to balance cross national and intra-national diversity. Journal of International Business Studies 39 (1), 41-46.

Ueltschy, L., Ryans, J.(1997). Advertising strategies to capitalize on Spain's second golden age. International Journal of Management 4 (13), 456-467.

Valente, T.W., Rogers, E.M.(1995). The origins and development of the diffusion of innovations paradigm as an example of scientific growth. Science Communication 16 (3), 242-273.

Venkatesh, V., Bala, H.(2008). Technology Acceptance Model 3 and a research agenda on interventions. Decision Sciences 39 (2), 273-315.

Venkatesh, V., Davis, F.D.(2000). A theoretical extension of the technology acceptance model: four longitudinal field studies. Management Science 46 (2), 186-204.

Venkatesh, V.(2000). Determinants of perceived ease of use: integrating control, intrinsic motivation, and emotion into the technology acceptance model. Information Systems Research 11 (4), 342-365.

Winsted, K.F.(1997). The service experience in two cultures: a behavioral perspective. Journal of Retailing 73 (3), 337-360.

Yaveroglu, I.S., Donthu, N.(2002). Cultural influences on the diffusion of new products. Journal of International Consumer Marketing 14 (4), 49-63.

Yavas, U., Verhage, B.J., Green, R.T.(1992). Global consumer segmentation versus local market orientation: empirical findings. Management International Review 32 (3), 265-273.

Zhang, P., von Dran, G.(2002). User expectations and rankings of quality factors in different web site domains. International Journal of Electronic Commerce 6 (2), 9-33.

Zhou, L., Dai, L., Zhang, D.(2007). Online shopping acceptance model - a critical survey of consumer factors in online shopping. Journal of Electronic Commerce Research 8(1), 